\title{
Prevalence of Work Stress among Private and Public Sector Employees in Delhi: A Differential Study
}

\author{
Jayeeta Biswas $^{1 *}$, Subodh Kumar ${ }^{2}$
}

\section{ABSTRACT}

Background: Stress is a term which is entangled with every stage of our lives - whether it is our workplace or our personal life. For the workplace, it may be the pressure to fulfill daily targets, deadline, must do project which arrives without warning, shared assignment or anything else which can generate stress. Lack of promotion, training and support from superiors lead to stress which in turn leads to higher rates of absenteeism, low productivity, low quality of product, customer dissatisfaction etc. Physical and mental health of an individual as well as organization's effectiveness can have the effect of work stress. Hence, the current study aimed to assess the prevalence of one of the mental health issues, i.e., stress, among private and public sector employees in Delhi, India. Methods: Purposive sampling technique was used to collect data from the private $(n=30)$ and public sector employees $(n=30)$. The level of stress was measured using Occupational Stress Index Scale (OSI Scale) questionnaire and demographic information sheet was used to collect various demographic information which includes age, gender, type of family, marital status, duration of service, salary, type of employment, educational qualification etc. Data was analyzed using SPSS (version 20.0) software. The chi-square test was used to find the relationship between categorical variables, pearson correlation coefficient was used to find the correlation between continuous variables according to distribution of the data. A p value less than 0.05 was considered as statistically significant. Results: The mean age of the participants was 38.62 $(\mathrm{SD}=8.79)$ years. According to OSI Scale, $13.3 \%$ employees (including both sectors) had low level of stress, $75 \%$ had moderate level of stress and $11.7 \%$ had high level of stress. Further, private sector employees had more work stress than the public sector employees. The results also indicate that Role Overload, Role Ambiguity, Role Conflict, Poor Participation, Powerlessness, Intrinsic Improvement, Low Status and Strenuous Working Condition had a significant relationship with the sector of employment. Conclusion: It was found that high level of stress was prevalent among employees in both the sectors - public and private. However, private sector employees were exposed to more professional stressors, which in turn created more occupational stress for them. It would be prudential for employers to initiate some training programmes related to physical and mental well-being, which can help enhance performance of employees and improve overall productivity of the organisation.

\footnotetext{
${ }^{1}$ Student, MA-Clinical Psychology, Indira Gandhi National Open University, New Delhi, India

${ }^{2}$ Research Scholar, Department of Psychology, Banaras Hindu University, Varanasi, Uttar Pradesh, India *Corresponding Author
}

Received: May 11, 2021; Revision Received: May 23, 2021; Accepted: June 21, 2021

(C) 2021, Biswas J.\& Kumar S.; licensee IJIP. This is an Open Access Research distributed under the terms of the Creative Commons Attribution License (www.creativecommons.org/licenses/by/2.0), which permits unrestricted use, distribution, and reproduction in any Medium, provided the original work is properly cited. 


\section{Prevalence of Work Stress among Private and Public Sector Employees in Delhi: A Differential Study}

Keywords: Stress, Occupational Stress, Job Stress, Work Stress, Public Sector, Private Sector

$\mathrm{S}$ tress is a state of mind which reflects certain biochemical reactions in the human body and is projected by a sense of anxiety, tension and depression and is caused by demands of the environmental forces or internal factors that cannot be met by the resources available with the person (Jit, 1995). It is also caused by a stimulus which can be either physical or psychological and an individual respond to the stimulus in some way (Moorhead \& Griffin, 2001). In other terms, we can define stress as a state of elevated activation of the autonomic nervous system with coordinated manifestations at the affective, cognitive, and behavioral levels (Siegrist \& Rodel, 2006) or as a dynamic condition in which an individual is confronted with an opportunity, constraint or demand related to what he/she desires and for which the outcome is perceived to be both uncertain and important (Stephen et al., 2007).

Any discomfort which is felt and perceived at a personal level and triggered by instances, events or situations that are too intense and frequent in nature so as to exceed a person's coping capabilities and resources to handle them adequately is called occupational stress (Malta, 2004). It can also be a series of physiological, psychological and behavioral responses due to the continuing effects of one or more stressors on individuals in an organization (Yan \& Xie, 2016). Chen \& Silverthorne (2008) labeled job stress as a workrelated psychological pressure and a worker's ability to respond and grip the specific situation at work place skillfully.

A healthy job is said to be the one where the amount of pressure on employees is according to their knowledge, abilities, resources, their control over the work and the support they receive from others. As health is not merely the absence of disease or infirmity but a positive state of complete physical, mental and social well-being (WHO, 1986), a healthy working environment is one in which there is not only an absence of harmful conditions but an abundance of health-promoting ones. The uncertainty and ambiguity in the environment (Gupta, 2018) and anxiety due to personal or professional reasons lead to stress, which then turns into depression (Alam, 2018). Lack of promotion, training, support from superiors lead to stress which in turn leads to higher rate of absenteeism, low productivity, low quality of product, customer dissatisfaction etc. Work stress is thought to affect individuals physical as well as psychological health as well as organization's effectiveness adversely. Employers face the challenge of fighting mental illness, which has a direct impact on productivity (Bisht, 2018).

As reported by Bhattacharya and Basu (2018), nearly half the employees in India suffer from some kind of stress, according to the latest survey by Optum. The survey was conducted among 800,000 employees in 70 large companies, each with a minimum workforce of 4,500. Another survey, conducted by 1 tolhelp.net, showed that the proportion of workers at high risk of suicide due to unmanaged stress has grown to $8 \%$ of all counselling cases in 2018 from 2-4\% two years ago.

Further, a qualitative study done on 51 employees in the oil sector conducted by Pandey and Dinyar (2017) has shown that work stress has been an important concern for both employers and employees in any industry. 60\% of employees find workplace stress so high that they want to quit their jobs (Roy, 2016). 


\section{Prevalence of Work Stress among Private and Public Sector Employees in Delhi: A Differential Study}

Bano, B. and Jha, R. K. (2012) reported that private sector employees face slightly more stress than those who are in the public sector. Also, educational qualification and work experience have a significant impact on employees' stress level.

According to a study done on occupational stress as experienced by private and public sector bank employees by Mokshagundam and Janardhanam (2016) reported that stress was more among employees of Private Sector Banks as compared to the employees of Public Sector Banks.

A study "Occupational Stress, Job Satisfaction \& Mental Health among Employees of Government and Non-government sector" conducted by Khundaniya and Kaji (2014) with a sample of 100 employees using OSI Scale showed that there was no significant difference among type of sector and gender with regards to their occupational stress, job satisfaction and mental health.

An empirical study done by Christiana and Mahalakshmi (2013) with 182 private sector managers and 120 public sector managers of Chennai has also reported that there was more or less the same level of stress in both the sectors.

Lehal (2007) conducted a research in Punjab to check Job Satisfaction and Organisational Role Stress in employees and reported that there was a negative correlation between job satisfaction and organizational role stress. Further, the research work of Bashir and Ramay (2010) on 144 samples from graduate, senior employees including managers and customers services officers of well reputed banks in Pakistan concluded that there was a negative correlation between job stress and job performances and shows that job stress significantly reduces the performance of an individual.

A survey done by Times Business Solutions (2016) reported that 35\% employees had developed insomnia, $30 \%$ felt tired \& fatigued all the time, loss of appetite was a major physical impact for $25 \%$ employees and $10 \%$ said that they had persistent body aches. Further, $40 \%$ of employees reported depression as the main consequence of workplace stress. Increased irritability had occurred to $25 \%$ employees, another $25 \%$ had complaints of increased incidences of anger and $10 \%$ had developed anxiety issues. While $60 \%$ employees wanted to quit their jobs because of workplace stress, $20 \%$ felt venting out helps them. For $10 \%$ employees, relaxation techniques such as deep breathing and meditation helped them cope with stress and another $10 \%$ took a break and went on vacation to recover from stress. 90\% of employees were interested in participating in corporate stress management programs, and $80 \%$ of them reported that there were no such programs offered by their organizations.

From various research and survey findings, we can say that work, money and family are the most common and main sources of stress. Other factors may be parenting, pregnancy, caregiving and social isolation. The purpose of this research was to study the prevalence of work stress among private and public sector employees in Delhi, India.

\section{METHODOLOGY}

\section{Sample}

We drew a purposive sample of 60 employees (30 from private sector and 30 from public sector) in Delhi, India. Questionnaires (in the google form) were sent to 350 private and 


\section{Prevalence of Work Stress among Private and Public Sector Employees in Delhi: A Differential Study}

public sector employees on their email addresses and non-respondents were reminded and sent the questionnaire up to two more times. Responses were received from 75 employees and as per the inclusion criteria of our study we selected only 60 responses. The sample is representative of the population from which it was drawn in terms of age, sex and employment sector. The final sample included 30 private and 30 public sector employees (17 Female, 43 Male) aged 25-60 years (mean=38.62, SD=8.79).

Table 1: Sociodemographic characteristics of participants

\begin{tabular}{|l|l|l|l|}
\hline Sociodemographic characteristics & \multicolumn{2}{|l|}{ \% } \\
\hline Gender & \multicolumn{2}{|l|}{} \\
\hline Female & 17 & 28.3 \\
\hline Male & 43 & 71.7 \\
\hline Marital status & \multicolumn{2}{|l|}{} \\
\hline Unmarried & 18 & 30 \\
\hline Married & 42 & 70 \\
\hline Family type & & \\
\hline Nuclear family & 39 & 65 \\
\hline Joint family & 21 & 35 \\
\hline Type of employment & & \\
\hline Permanent & 34 & 66.7 \\
\hline Contractual & 26 & 43.3 \\
\hline Note. Participants were on average 38.62 (SD=8.79) years old. & & \\
\hline
\end{tabular}

Tools

In the present study Occupational Stress Index scale developed by A.K. Srivastav and A.P. Singh was used. In this scale minimum 46 and maximum 230 score could be obtained based on the 5 options set in the scale. The scoring was done as 5 for 'Strongly Agree', 4 for 'Agree', 3 for 'Uncertain', 2 for 'Disagree', 1 for 'Strongly Disagree'. The interpretation was done as; if the score is below 122, the employee has low stress, if it is between 123 to 155 , the stress is moderate and if it is more than 156 , the employee is highly stressed. o be rated on the five-point scale. Out of 46 items, 27 were true-keyed and the rest 19 were falsekeyed. For a false-keyed answer the score was reversed. The items relate to almost all relevant components of the job life, which cause stress in some way or other, such as role overload, role ambiguity, role conflict, group, and political pressures, responsibility for subordinates, poor participation, powerlessness, poor peer relations, intrinsic 


\section{Prevalence of Work Stress among Private and Public Sector Employees in Delhi: A Differential Study}

impoverishment, low status, strenuous working conditions, and unprofitability. These items in this scale are related to almost all relevant components of the work life, which cause stress in some way. Occupational stress index covered 12 dimensions- such as role overload, role ambiguity, role conflict, group, and political pressures, responsibility for subordinates, poor participation, powerlessness, poor peer relations, intrinsic impoverishment, low status, strenuous working conditions, and unprofitability.

Reliability and Validity of OSI Scale: The reliability of OSI Scale was measured through a split half (odd even) method and the Cronbach's alpha coefficient for the mail scale was 0.935 and 090 respectively. The reliability of 12 sub scales are found to be rightly reliable by using reliable by split half method. The validity was measured by computing the correlation coefficient (r-value) between OSI scores and various job attributes and job behavior. And it was found that there is a highly significant positive correlation between them.

Demographic Information Sheet: Demographic information sheet was used to collect various demographic information about the sample including age, gender, type of family, qualification, and marital status. Apart from that, information of other variables like no. of children, family type, monthly family income, sector of employment, employment type, years of experience, duration of employment, any illness, working mode during COVID-19 pandemic and area of living were also collected.

\section{Statistical Analysis}

The data was analyzed using statistical software SPSS (version 20.0). Continuous variables were presented in the form of mean $( \pm \mathrm{sd})$ and categorical variables were presented as number (\%). To find the association between categorical variables, the Chi-Square test was used. Pearson correlation was used to find the correlation between continuous variables according to distribution of the data. A $p$ value less than 0.05 was considered as statistically significant.

\section{RESULTS}

The mean age of the participants was $38.62(\mathrm{SD}=8.79)$ years. $71.7 \%(\mathrm{n}=43)$ were male and $28.3 \%(n=17)$ were female. Further, $70 \%(n=42)$ were married and $30 \%(n=18)$ were unmarried.

It was observed that among the total employees in both the sectors, $13.3 \%$ employees had low stress level, $75 \%$ had moderate stress level and $11.7 \%$ had high stress level on OSI scale (Table 2).

As per OSI sub-scales, majority of the participants had low level of Role Ambiguity (63.3\%) \& Low Status (56.7\%), moderate level of Role Overload (71.7\%), Role Conflict (50\%), Unreasonable Group and Political Pressure (61.7\%), Responsibility for Subordinates (73.3\%), Powerlessness (60\%) \& Poor Peer Relations (58.3\%), and high level of Poor Participation (46.7\%), Intrinsic Improvement (60\%), Strenuous Working Condition (46.7\%) \& Unprofitability (70\%). (Table 2). 
Prevalence of Work Stress among Private and Public Sector Employees in Delhi:

A Differential Study

Table 2: Level of Stress among employees

\begin{tabular}{|l|l|l|l|}
\hline Scale/ Subscales & Low $(\boldsymbol{\%})$ & Moderate $(\%)$ & High (\%) \\
\hline OSI & 13.3 & 75.0 & 11.7 \\
\hline Role overload & 6.7 & 71.7 & 21.7 \\
\hline Role Ambiguity & 63.3 & 23.3 & 13.3 \\
\hline Role Conflict & 38.3 & 50.0 & 11.7 \\
\hline $\begin{array}{l}\text { Unreasonable Group and Political } \\
\text { Pressure }\end{array}$ & 8.3 & 61.7 & 30 \\
\hline Responsibility for Subordinates & 13.3 & 73.3 & 13.3 \\
\hline Poor Participation & 26.7 & 26.7 & 46.7 \\
\hline Powerlessness & 25.0 & 60.0 & 15.0 \\
\hline Poor Peer Relations & 10.0 & 58.3 & 31.7 \\
\hline Intrinsic Improvement & 15.0 & 25.0 & 60.0 \\
\hline Low Status & 56.7 & 28.3 & 15.0 \\
\hline Strenuous Working Condition & 15.0 & 38.3 & 46.7 \\
\hline Unprofitability & 5.0 & 25.0 & 70.0 \\
\hline
\end{tabular}

The result presented in table 3 shows that the mean value (140.36) of Private sector is more than the mean value (136.43) of Public Sector for OSI scale which clearly indicates that the private sector employees had more occupational stress than public sector employees.

Further, the mean scores of private sector employees for the Subscale; Role Overload, Role Ambiguity, Role Conflict, Poor Peer Relations, Low Status, Strenuous Working Conditions and Unprofitability are more than mean scores of public sector employees. But, the mean scores of private sector employees for Unreasonable Group and Political Pressure, Responsibility for Subordinates, Poor Participation, Powerlessness and Intrinsic Improvement are less than the mean scores of public sector employees. These results indicate that private sector employees had more Role Overload, Role Ambiguity, Role Conflict, Poor Peer Relations, Low Status, Strenuous Working Conditions \& Unprofitability and less Unreasonable Group and Political Pressure, Responsibility for Subordinates, Poor Participation, Powerlessness and Intrinsic Improvement than public sector employees or vice-versa. 
Prevalence of Work Stress among Private and Public Sector Employees in Delhi:

A Differential Study

Table 3: Mean and Standard Deviation of the Scales/ Subscales and Sector of Employment.

\begin{tabular}{|l|l|l|l|l|}
\hline \multirow{2}{*}{ Scale/ Subscales } & \multicolumn{4}{l}{ Sector of employment } \\
\cline { 2 - 5 } & \multicolumn{2}{l}{ Private Sector (N=30) } & \multicolumn{2}{l|}{ Public Sector (N=30) } \\
\cline { 2 - 5 } & Mean & SD & Mean & SD \\
\hline OSI & 140.36 & 23.62 & 136.43 & 6.62 \\
\hline Role overload & 20.13 & 4.18 & 18.73 & 1.91 \\
\hline Role Ambiguity & 10.96 & 2.05 & 7.13 & 0.56 \\
\hline Role Conflict & 14.3 & 3.46 & 13.46 & 1.54 \\
\hline $\begin{array}{l}\text { Unreasonable Group and Political } \\
\text { Pressure }\end{array}$ & 12.00 & 3.13 & 14.33 & 0.82 \\
\hline Responsibility for Subordinates & 9.8 & 2.42 & 10.36 & 1.27 \\
\hline Poor Participation & 10.2 & 4.39 & 13.76 & 1.64 \\
\hline Powerlessness & 7.83 & 3.00 & 8.93 & 1.09 \\
\hline Poor Peer Relations & 12.46 & 4.21 & 11.46 & 1.52 \\
\hline Intrinsic Improvement & 11.76 & 3.92 & 13.7 & 1.65 \\
\hline Low Status & 9.06 & 2.96 & 5.93 & 0.51 \\
\hline Strenuous Working Condition & 13.9 & 2.71 & 11.23 & 2.69 \\
\hline Unprofitability & 7.93 & 1.98 & 7.36 & 0.91 \\
\hline
\end{tabular}

The results presented in Table 4 indicate that Role Overload, Role Ambiguity, Role Conflict, Poor Participation, Powerlessness, Intrinsic Improvement, Low Status and Strenuous Working Condition have a significant relationship with the sector of employment.

Table 4: Level of stress among private \& public sector employees and p value.

\begin{tabular}{|l|l|l|l|l|}
\hline \multirow{2}{*}{ Scale/ Subscales } & \multirow{2}{*}{ Level } & \multicolumn{3}{|l|}{ Sector of employment } \\
\cline { 3 - 4 } & & Private (\%) & Public (\%) & $\boldsymbol{p}$ value \\
\hline \multirow{2}{*}{ OSI } & Low & 23.3 & 3.3 & \multirow{2}{*}{0.798} \\
\cline { 2 - 4 } & Moderate & 53.3 & 96.7 & \\
\cline { 2 - 4 } & High & 23.3 & 0.0 & \multirow{2}{*}{0.024} \\
\hline \multirow{2}{*}{ Role overload } & Low & 13.3 & 0.0 & \\
\cline { 2 - 4 } & Moderate & 43.3 & 100.0 & \\
\hline
\end{tabular}


Prevalence of Work Stress among Private and Public Sector Employees in Delhi:

A Differential Study

\begin{tabular}{|c|c|c|c|c|}
\hline \multirow[t]{2}{*}{ Scale/ Subscales } & \multirow[t]{2}{*}{ Level } & \multicolumn{3}{|c|}{ Sector of employment } \\
\hline & & Private $(\%)$ & Public (\%) & $p$ value \\
\hline & High & 43.3 & 0.0 & \\
\hline \multirow[t]{3}{*}{ Role Ambiguity } & Low & 26.7 & 100.0 & \multirow[t]{3}{*}{0.000} \\
\hline & Moderate & 46.7 & 0.0 & \\
\hline & High & 26.7 & 0.0 & \\
\hline \multirow[t]{3}{*}{ Role Conflict } & Low & 30.0 & 46.7 & \multirow[t]{3}{*}{0.019} \\
\hline & Moderate & 46.7 & 53.3 & \\
\hline & High & 23.3 & 0.0 & \\
\hline \multirow{3}{*}{$\begin{array}{l}\text { Unreasonable Group and Political } \\
\text { Pressure }\end{array}$} & Low & 16.7 & 0.0 & \multirow[t]{3}{*}{0.122} \\
\hline & Moderate & 56.7 & 66.7 & \\
\hline & High & 26.7 & 33.3 & \\
\hline \multirow{3}{*}{ Responsibility for Subordinates } & Low & 20.0 & 6.7 & \multirow[t]{3}{*}{0.321} \\
\hline & Moderate & 53.3 & 93.3 & \\
\hline & High & 26.7 & 0.0 & \\
\hline \multirow[t]{3}{*}{ Poor Participation } & Low & 53.3 & 0.0 & \multirow[t]{3}{*}{0.000} \\
\hline & Moderate & 20.0 & 33.3 & \\
\hline & High & 26.7 & 66.7 & \\
\hline \multirow[t]{3}{*}{ Powerlessness } & Low & 50.0 & 0.0 & \multirow[t]{3}{*}{0.040} \\
\hline & Moderate & 26.7 & 93.3 & \\
\hline & High & 23.3 & 6.7 & \\
\hline \multirow[t]{3}{*}{ Poor Peer Relations } & Low & 20.0 & 0.0 & \multirow[t]{3}{*}{0.058} \\
\hline & Moderate & 23.3 & 93.3 & \\
\hline & High & 56.7 & 6.7 & \\
\hline \multirow[t]{3}{*}{ Intrinsic Improvement } & Low & 30.0 & 0.0 & \multirow[t]{3}{*}{0.003} \\
\hline & Moderate & 23.3 & 26.7 & \\
\hline & High & 46.7 & 73.3 & \\
\hline \multirow[t]{2}{*}{ Low Status } & Low & 23.3 & 90.0 & \multirow[t]{2}{*}{0.000} \\
\hline & Moderate & 46.7 & 10.0 & \\
\hline
\end{tabular}

(c) The International Journal of Indian Psychology, ISSN 2348-5396 (e) | ISSN: 2349-3429 (p) | 1383 


\begin{tabular}{|l|l|l|l|l|}
\hline \multirow{3}{*}{ Scale/ Subscales } & \multirow{2}{*}{ Level } & \multicolumn{3}{|l|}{ Sector of employment } \\
\cline { 3 - 4 } & & Private (\%) & Public (\%) & p value \\
\cline { 2 - 4 } & High & 30.0 & 0.0 & \\
\hline \multirow{3}{*}{ Strenuous Working Condition } & Low & 3.3 & 26.7 & \multirow{2}{*}{$\mathbf{0 . 0 0 0}$} \\
\cline { 2 - 4 } & Moderate & 26.7 & 50.0 & \\
\cline { 2 - 4 } & High & 70.0 & 23.3 & \multirow{2}{*}{0.823} \\
\hline \multirow{3}{*}{ Unprofitability } & Low & 10.0 & 0.0 & \\
\cline { 2 - 4 } & Moderate & 16.7 & 33.3 & 66.7 \\
\cline { 2 - 4 } & High & 73.3 & & \\
\hline
\end{tabular}

\section{DISCUSSION}

Higher level of stress among private sector employees have a great impact on employees as well as employers also in terms of reduced productivity and increased staff turnover. For employees it may lead to work life disbalance, it also has a negative impact on family and social interactions. Impact of higher level of OSI Score on health include: cardiovascular disease like obesity, high blood pressure, high blood cholesterol even heart attack and stroke immune deficiency disorders, musculo-skeletal disorders and Gastrointestinal disorders.

The present study revealed that more $86.7 \%$ of employees had moderate or high level of stress on OSI scale and majority of the participants had low level of Role Ambiguity (63.3\%) \& Low Status (56.7\%), moderate level of Role Overload (71.7\%), Role Conflict (50\%), Unreasonable Group and Political Pressure (61.7\%), Responsibility for Subordinates (73.3\%), Powerlessness (60\%) \& Poor Peer Relations (58.3\%), and high level of Poor Participation (46.7\%), Intrinsic Improvement (60\%), Strenuous Working Condition (46.7\%) \& Unprofitability $(70 \%)$. It shows that the job stress among the employees was due to various reasons.

The mean value of Private sector (140.36) and the Public Sector (136.43) for OSI scale indicates that the private sector employees had more occupational stress than public sector employees.

The results further indicate that private sector employees might have high stress due to Role Overload, Role Ambiguity, Role Conflict, Poor Peer Relations, Low Status, Strenuous Working Conditions and Unprofitability. But, the public sector employees might have high stress due to the Unreasonable Group and Political Pressure, Responsibility for Subordinates, Poor Participation, Powerlessness and Intrinsic Improvement. These results also indicate that private sector employees had more Role Overload, Role Ambiguity, Role Conflict, Poor Peer Relations, Low Status, Strenuous Working Conditions \& Unprofitability and less Unreasonable Group and Political Pressure, Responsibility for Subordinates, Poor Participation, Powerlessness and Intrinsic Improvement than public sector employees or vice-versa. 


\section{Prevalence of Work Stress among Private and Public Sector Employees in Delhi: A Differential Study}

\section{CONCLUSION}

Our results show that the employees in the private sector had more stress than in the public sector. We also found that Role Overload, Role Ambiguity, Role Conflict, Poor Participation, Powerlessness, Intrinsic Improvement, Low Status and Strenuous Working Condition had a significant relationship with the sector of employment i.e., private and public sector. According to our results, private organisations should pay more attention in improving the well-being of their employees and the psychosocial profile of their organizations. To reduce stress in order to enhance the performance as well as bring a positive personality trait to maintain a good work life balance so as to improve productivity, some training modules should be introduced. Stress coping programmes for physical and mental well-being should also be introduced as a part of employees' wellbeing initiative and employees should also take their own initiative to reduce stress through mindfulness.

\section{Implications}

Policy Makers: The concerned authorities should implement job descriptions that are more or less consistent to the job roles in order to bring in basic clarity of roles, to reduce ambiguity and conflicts in roles especially with respect to private sector, since the private sector employees are more at risk for burnout and occupational stress when compared to public sector in the present study. The employers could take initiative in introducing some kind of physical and mental well-being training programmes that can enhance the performance of the employees and improve productivity of the organisation. Managers of private and public sectors can take initiative to minimize role overload, role conflict (creating policies and practices that do not place the executives dealing with clients directly in difficult situations), role ambiguity (clearly define duties and responsibilities), poor participation, strenuous working conditions and intrinsic improvement.

\section{Limitations of the Study}

The sample size for this study was restricted to only 60 (30 from private sector and 30 from public sector) to represent the population in Delhi, India and the data collection was done online due to the COVID-19 pandemic situation which might affect certain factors in the outcome of the research as the responses were recorded under uncontrolled environment. The study did not cover every part of India. It was restricted only to Delhi, India. There may be sampling issues as the data was collected online using Google form due to COVID 19 pandemic i.e. there are chances of participants not providing accurate information. Some promotional schemes could be given to the participants for providing the real data so that the study would have been more accurate. Some participants might hide true expression or misrepresent their identity or their true feelings about the content of the questionnaire. This study suggests that some further studies should also be done across states of India on a larger population.

\section{REFERENCES}

Ahmed, Oli \& Khanam, Mahfuza. (2018). Perceived Organizational Support, Job Stress, Job Satisfaction, and Organizational Commitment among NGO Employees. 28. 101-114.

Anxiety Disorders Association of America (ADAA, 2017). Anxiety and Stress in the Workplace. Retrieved from https://adaa.org/managing-stress-anxiety-inworkplace/anxiety-disorders-in-workplace

Anxiety Disorders Association of America (ADAA, 2006). Workplace Stress \& Anxiety Disorders Survey: Highlights. Retrieved from https://adaa.org/workplace-stressanxiety-disorders-survey 


\section{Prevalence of Work Stress among Private and Public Sector Employees in Delhi: A Differential Study}

Bano, B. \& Jha, RK.(2012).Organizational Role Stress among Public and Private Sector Employees: A comparative Study. The Lahore Journal of Business 1:1 (Summer 2012): pp. 23-36.DOI: 10.35536/ljb.2012.v1.i1.a2

Bhattacharyya, R., Basu \& DS. (2018). India Inc looks to deal with rising stress in employees.

Retrieved from https://economictimes.indiatimes.com/jobs/india-inc-looks-to-dealwith-rising-stress-in-employees/articleshow/64741313.cms

Brun, JP. (2007). Work-related stress: scientific evidence-base of risk factors, prevention and costs. Retrieved from

https://www.who.int/occupational_health/topics/brunpres0307.pdf

Cardozo,LB. \& Crawford,GC., Eriksson, C., Zhu, J., Sabin, M., Ager,A.(2012).Psychological Distress, Depression, Anxiety, and Burnout among International Humanitarian Aid Workers: A Longitudinal Study. PLOS ONE 7(9): e44948. https://doi.org/10.1371/journal.pone.0044948

Chappelow,J. (2020). Private Sector. Retrieved from https://www.investopedia.com/terms/p/private-sector.asp

Christiana, MBV. \& Mahalakshmi,V. (2013): Role Stress and its Impact on Public and Private Sector Manager in Chennai: An Empirical Study. International Journal of Management \& Business Studies, Vol. 3, Issue 1. Retrieved from http://www.ijmbs.com/31/beulah.pdf

Djindjic, N., Jovanovic, J., Djindjic, B., Jovanovic, M. \& Jovanovic, JJ. (2012).Associations between the Occupational Stress Index and Hypertension, Type 2 Diabetes Mellitus, and Lipid Disorders in Middle- Aged Men and Women. Ann Occup Hyg. 2012 Nov;56(9):1051-62. doi: 10.1093/annhyg/mes059. Epub 2012 Sep 17. PMID: 22986427.

LeBlanc, NJ. \& Marques, L. (2019). How to handle stress at work. Harvard Health Blog. Retrieved from https://www.health.harvard.edu/blog/how-to-handle-stress-at-work2019041716436

Malamardi, S. N., Kamath, R., Tiwari, R., Nair, B. V., Chandrasekaran, V., \& Phadnis, S. (2015). Occupational stress and health-related quality of life among public sector bank employees: A cross-sectional study in Mysore, Karnataka, India. Indian journal of occupational and environmental medicine, 19(3), 134-137. https://doi.org/10.4103/0019-5278.173998

Maulik, PK. (2018). Workplace stress: A neglected aspect of mental health wellbeing.Indian J Med Res 2017;146:441-4.DOI: 10.4103/ijmr.IJMR_1298_17

Mokshagundam, SS. \& Janardhanam, K.(2016). A study on Occupational Stress as Experienced by Private and Public Sector Bank Employees. International Journal of Engineering and Management Research (IJEMR), Vol 6, Issue 3. Retrieved from http://www.indianjournals.com/ijor.aspx?target=ijor:ijemr\&volume=6\&issue $=3 \&$ artic le $=012$

Pandey, S. \& Pestonjee, D. M. (2018). A qualitative study of work stress and employees' expectations of stress management interventions in context of indian oil \& gas industry professionals. In D. M. Pestonjee and R. Naranedran (Eds) Sustainable development of human capital: Exploring perspectives from grassroots to global research and practice (pp. 330-347), New Delhi: Excel Publications

Segal, J., Smith, M., Robinson \& L.,Segal, R. (2019). Stress in the Workplace: Managing Job and Work Stress. HelpGuide. Retrieved from https://www.helpguide.org/articles/stress/stress-in-the-workplace.htm

Sindwani, P.(2019).Always On' work culture is affecting mental health of Indians. ET

(c) The International Journal of Indian Psychology, ISSN 2348-5396 (e) | ISSN: 2349-3429 (p) | 1386 


\section{Prevalence of Work Stress among Private and Public Sector Employees in Delhi: \\ A Differential Study}

Bureau. Retrieved from https://economictimes.indiatimes.com/magazines/panache/89per-cent-of-indias-population-suffering-from-stress-most-dont-feel-comfortabletalking-to-medical-professionals

WHO (2019). Mental health in the workplace. Retrieved

from https://www.who.int/mental_health/in_the_workplace/en/

Wikipedia (2019). Public Sector. Retrieved from https://en.wikipedia.org/wiki/Public_sector

\section{Acknowledgement}

The author(s) appreciates all those who participated in the study and helped to facilitate the research process.

\section{Conflict of Interest}

The author(s) declared no conflict of interest.

How to cite this article: Biswas, J. \& Kumar, S. (2021). Prevalence of Work Stress Among Private and Public Sector Employees in Delhi: A Differential Study. International Journal of Indian Psychology, 9(2), 1376-1387. DIP:18.01.142.20210902, DOI:10.25215/0902.142 